\title{
Demography of feral camels in central Australia and its relevance to population control
}

\author{
A. R. Pople $\mathrm{A}^{\mathrm{A}}$ and S. R. McLeod ${ }^{\mathrm{B}}$ \\ A Biosecurity Queensland, Primary Industries and Fisheries, Department of Employment, Economic Development \\ and Innovation, Alan Fletcher Research Station, PO Box 36, Sherwood, Qld 4075, Australia. \\ ${ }^{B}$ Vertebrate Pest Research Unit, New South Wales Department of Primary Industries, Forest Road, Orange, \\ NSW 2800, Australia. \\ ${ }^{\mathrm{C}}$ Corresponding author. Email: Tony.Pople@deedi.qld.gov.au
}

\begin{abstract}
Since their release over 100 years ago, camels have spread across central Australia and increased in number. Increasingly, they are being seen as a pest, with observed impacts from overgrazing and damage to infrastructure such as fences. Irregular aerial surveys since 1983 and an interview-based survey in 1966 suggest that camels have been increasing at close to their maximum rate. A comparison of three models of population growth fitted to these, albeit limited, data suggests that the Northern Territory population has indeed been growing at an annual exponential rate of $r=0.074$, or $8 \%$ per year, with little evidence of a density-dependent brake. A stage-structured model using life history data from a central Australian camel population suggests that this rate approximates the theoretical maximum. Elasticity analysis indicates that adult survival is by far the biggest influence on rate of increase and that a $9 \%$ reduction in survival from $96 \%$ is needed to stop the population growing. In contrast, at least $70 \%$ of mature females need to be sterilised to have a similar effect. In a benign environment, a population of large mammals such as camels is expected to grow exponentially until close to carrying capacity. This will frustrate control programs, because an ever-increasing number of animals will need to be removed for zero growth the longer that culling or harvesting effort is delayed. A population projection for 2008 suggests 10500 animals need to be harvested across the Northern Territory. Current harvests are well short of this. The ability of commercial harvesting to control camel populations in central Australia will depend on the value of animals, access to animals and the presence of alternative species to harvest when camels are at low density.
\end{abstract}

Additional keywords: fertility control, harvesting, population dynamics.

\section{Introduction}

Camels (Camelus dromedarius) were introduced into Australia from the 1840 s to the early 1900 s for transport and hauling cargo in arid regions. Edwards et al. (2004) suggested that prior to 1920, the feral population of camels would have been small and scattered. However, by the 1930 s, camels had become superseded by motor vehicles and rail for transport and consequently around 5000 captive camels were released between 1920 and 1941 (McKnight 1969; Edwards et al. 2004).

In 1966, McKnight (1969) estimated from interviews that there were between 15000 and 20000 wild camels in Australia; 4500 to 6000 of these in the Northern Territory. Between 1983 and 2001, aerial surveys (Graham et al. 1986; Short et al. 1988; Wurst and Saalfeld 1994; Edwards et al. 2004) indicated a population in the Northern Territory that was growing at $\sim 10 \%$ per year; a rate that appears to have been maintained since the 1960s. Edwards et al. (2004) noted that this rate of increase approaches the maximum rate for camels, partly a result of the lack of natural predators in Australia, but also because food is rarely limiting. They raised the concern that this near exponential rate of increase would continue unchecked for some time. Despite already having demonstrable impacts, wild camels have not been seen as a major pest by the wider community. The call is, thus, for present action to alleviate future costs (Edwards et al. 2008b).

Camels can have a detrimental impact on vegetation through overgrazing and, to a lesser extent, trampling (Edwards et al. 2008a). Other impacts of wild camels include competition with domestic stock, fouling of waterholes, destabilising of dune crests, damage to stock fences and social impacts such as damaging sites of cultural significance and being a motoring hazard (Edwards et al. 2004, 2008a). All of the above impacts are exacerbated, at least on a local scale, when camels form large herds.

The current and future size of these impacts will depend on the relationship between density and impact, the distribution of camels and the distribution of the environmental, economic and social 'assets' that are affected. The relationship between density and impact is unlikely to be linear, but is likely to vary spatially 
and temporally. Following a review of studies of impacts of camels, Edwards et al. (2008a) recommended camels be controlled to broad-scale densities of $0.1-0.2$ camels $/ \mathrm{km}^{2}$ to mitigate damage.

The three main options to control the impacts of camels include (Edwards et al. 2004; Saalfeld and Zeng 2008; Zeng and McGregor 2008):

(1) exclusion fencing;

(2) commercial harvesting including capture and domestication by landholders, resulting in the sale of camel products; and

(3) ground-based and aerial culling where camel products are not sold.

Fertility control is a further option (Hone 1992), but a species-specific method would need to be developed as would its broad-scale delivery (Lapidge et al. 2008). Given the life history of camels (i.e. high adult survival and low fecundity), control techniques will be most effective when they target adult survival.

However, the low densities, high mobility and low water requirements of camels will make their control difficult. Aerial shooting and trapping at water points has reduced the numbers of feral horses and donkeys in several areas of arid South Australia, Western Australia and the Northern Territory. In contrast to these species, camels form smaller herds and visit water points less frequently, reducing the effectiveness of these techniques. However, during drought, camels aggregate near water points and where there are remnant food supplies, which offers an opportunity for reducing numbers at a time when their impact is greatest. 'Judas' camels (Parkes et al. 1996; Edwards et al. 2004) could also be used to enhance culling and harvesting programs.

Commercial harvesting of camels may provide some reduction in population size, or at least a reduction in the rate of population growth. However, it will be economic to harvest camels only above a certain density and only in accessible areas. Throughout much of their distribution, camels exist at low densities (<2 camels $/ \mathrm{km}^{2}$, Edwards et al. 2004; Saalfeld and Edwards 2008) and much of their habitat is remote and difficult to access. Hence, their spatially variable and generally low density, combined with a punctuated, presently unpredictable pattern of ranging over large areas (Grigg et al. 1995; Edwards et al. 2001), makes harvesting difficult and costly. Increasing the value of camels and the availability of other species to harvest will make it more profitable to reduce camel populations to low densities and hold them there.

This study reassesses the growth of the Northern Territory camel population using population estimates presented by Edwards et al. (2004). In particular, population models other than exponential growth that incorporate density dependence should be considered. The theoretical maximum rate can be determined from an age structured model using life history data recorded by Dörges and Heucke (1995). These models can also be used to quantify the amount of control required to suppress growth either through harvesting, culling or fertility control.

\section{Materials and methods}

Unstructured and stage-structured temporal models were used to examine the impact of harvesting and fertility control on population size.

\section{Unstructured models}

It was not possible to determine a priori which model would provide the best fit to the time series data of camel abundance in the Northern Territory. Therefore, we chose to test three alternative models that were: (i) the exponential model (Eqn 1), (ii) the logistic model (Eqn 2) and (iii) the theta-logistic model (Eqn 3).

$$
\begin{gathered}
N_{t+1}=N_{t} e^{r_{m}} \\
N_{t+1}=N_{t} e^{r_{m}\left(1-\left(\frac{N_{t}}{K}\right)\right)} \\
N_{t+1}=N_{t} e^{r_{m}\left(1-\left(\frac{N_{t}}{K}\right)^{\ominus}\right)}
\end{gathered}
$$

Here, $r_{m}$ is the maximum exponential rate of increase, $N_{t}$ is population size at time $t, K$ is carrying capacity and theta $(\theta)$ is a term influencing the strength of density dependence relative to $K$.

The exponential model characterises populations showing unbounded growth which might be representative of the dynamics of a camel population in the Northern Territory that is not close to carrying capacity. The logistic model might more closely represent the dynamics of a camel population that is approaching carrying capacity and the population's size is starting to asymptote and rate of increase is declining linearly with increasing density. The theta-logistic model would be favoured if the rate of increase of the population is a nonlinear function of density. If $\theta<1$, density dependence is strong even when the population is far below carrying capacity. By contrast, if $\theta>1$, density dependence is weak until the population is close to carrying capacity (Rockwood 2006).

Large mammals typically show most density-dependent changes in rate of increase at densities close to carrying capacity (Fowler 1981, 1987). In other words, density-independent limiting factors aside (i.e. a benign environment), population growth will tend to be exponential until close to carrying capacity (Fig. 1) when resources become limiting due to crowding. This pattern of population growth can be modelled using a thetalogistic (or generalised logistic) model (e.g. Eberhardt 1987), with greater values of theta indicating the increasing proximity of

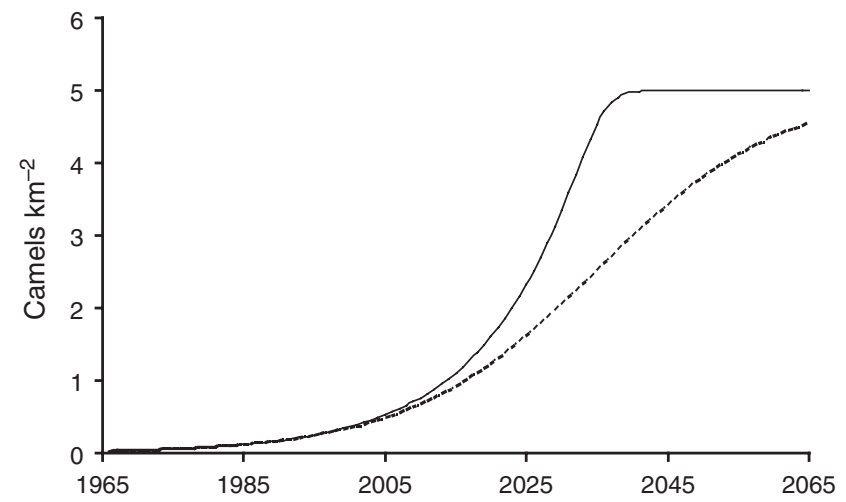

Fig. 1. Potential growth for the southern Northern Territory camel population according to the theta-logistic model when $\theta=1$ (dashed line) and $\theta=7$ (solid line). In both cases, $K$ is arbitrarily set at 5 camels $/ \mathrm{km}^{2}$ and $r_{m}=0.074$. Population density in 1966 is assumed to be 0.029 camels $/ \mathrm{km}^{2}$ (Edwards et al. 2004). 
density to carrying capacity before density dependence becomes severe. When $\theta=1$, the theta-logistic model is equivalent to the logistic model.

One use of this model is the calculation of the productivity of the population at various densities (Fig. 2). This is known as a yield curve, indicating the sustained harvest that can be taken from the modelled population while holding it at an equilibrium density (i.e. exponential rate of increase, $r=0$ ) below carrying capacity. The maximum point of the yield curve is the maximum sustained yield (MSY). Assuming logistic growth, the MSY is at $0.5 \mathrm{~K}$. Using the theta logistic model with $\theta>1$, the MSY is pushed to the right (i.e. $>0.5 K$ ). In both Figs 1,2 , theta has been arbitrarily set to 7, but is consistent with values used for other large mammals (Eberhardt 1987), and the value for $K$ is also arbitrary apart from being greater than current population density.

\section{Parameter estimation}

Parameters for each model were estimated by maximum likelihood, assuming that observation errors followed a lognormal distribution (Hilborn and Mangel 1997). To estimate parameters for these models we used population estimates for camels in the southern Northern Territory $\left(\sim 259000 \mathrm{~km}^{2}\right)$ reported by Edwards et al. (2004). The analysis also enabled us to revisit their estimates of current and historical rates of increase in that camel population. The observed data against which the models were fitted are presented in Table 1. A more conservative factor of 1.54 was used to correct population estimates for visibility bias for surveys before 2001 rather than 1.81 used by Edwards et al. (2004). This lower value represents the overall correction factor for the 2001 survey estimate.

\section{Stage-structured model}

Accurate projection matrices require detailed demographic data which are largely absent for camels in Australia. The most complete dataset was collected by Dörges and Heucke (1995), who studied a captive population in a large enclosure in central Australia.

Dörges and Heucke (1995) estimated that wild-living camels live to $\sim 30$ years of age, but camels can live to 40 years of age (Carey and Judge 2001). We estimated that cohorts of age 31-40 make up about only $2 \%$ of the population, so have included these

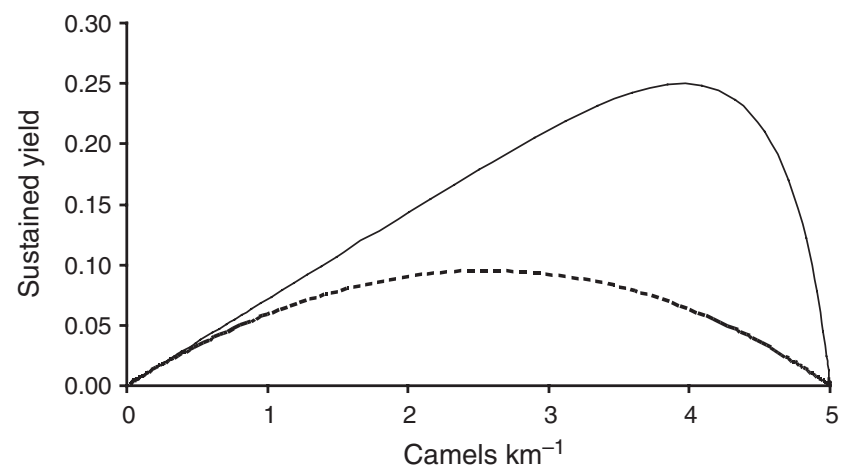

Fig. 2. Sustained yield (harvested camels $/ \mathrm{km}^{2}$ ) plotted against density (camels $/ \mathrm{km}^{2}$ ) for a theta-logistic model (solid line) of camel population growth with $\theta=7, K=5 \mathrm{camels} / \mathrm{km}^{2}$ and $r_{m}=0.074$, and a logistic model (dashed line) with $K=5$ camels $/ \mathrm{km}^{2}$ and $r_{m}=0.074$. age classes in our analyses. They observed that camels bred all year round (but with a distinct increase in the frequency of births between June and November) and we have assumed that camels in central Australia are continuous breeders and that first breeding occurs at 5 years of age. The birth interval of most mature females was 22.2 months ( 1.85 years). However, females that lost a newborn were able to give birth after 14.4 months ( 1.2 years). To take this difference into account we used a weighted average birth interval of 19.9 months (1.66 years). Dörges and Heucke (1995) also noted that female fertility rate was $100 \%$, but that $29 \%$ of newborns died soon after birth. They also estimated that camels older than 1 year had a survival rate of $96 \%$ per year. These estimates of reproductive output and survival come from the southern Northern Territory during the late 1980s and early 1990s. There is little scope to improve on these vital rates, so they should generate a rate of increase that is close to the maximum. To model these parameters, the projection interval was one year.

We used these estimates as initial values for the projection matrix transition probabilities. Final values for transition probabilities were derived by minimising the sum of squared errors between the size of the structured population and the best unstructured model (see below). The Microsoft Excel add-in 'Solver' was used to minimise the sum-of-squares.

The structured model comprised three stage classes: (i) yearlings, (ii) subadults (ages 1-5), and (iii) adults (ages 6-40), connected according to the life-cycle shown in Fig. 3 to describe the population dynamics.

Following the methods described by Caswell (2001), we used the following equations to calculate transition probabilities $\left(P_{i}, G_{i}\right.$ and $F_{i}$ ) for the projection matrix (Fig. 4):

$$
\begin{gathered}
P_{i}=\sigma_{i}\left(1-\gamma_{i}\right) \\
G_{1}=\sqrt{\sigma_{1}} \\
G_{i}=\sigma_{i} \gamma_{i} \\
F_{2}=\sqrt{\sigma_{1}} \mathrm{G}_{2} \frac{m_{2}}{2} \\
F_{3}=\sqrt{\sigma_{1}}\left(\frac{\left(1+P_{3}\right) m_{3}}{2}\right)
\end{gathered}
$$

where $\sigma_{i}$ is the survival probability (one minus the ratio of deaths in stage $i$ to the number of individual-years of exposure in stage $i$ ),

Table 1. Estimated population size (or observed population size) of the feral camel population in the Northern Territory between 1966 and 2001 Estimates from 1983 (Short et al. 1988), 1984 (Graham et al. 1986), 1993 (Wurst and Saalfeld 1994) and 2001 (Edwards et al. 2004) are from aerial surveys and have been corrected for animals potentially missed by observers. The 1966 estimate is based on interviews with landholders (McKnight 1969). See Edwards et al. (2004) for details

\begin{tabular}{cccc}
\hline Year & Uncorrected number & Corrected number & $95 \% \mathrm{CI}$ \\
\hline 1966 & $4500-6000$ & - & - \\
1983 & 11600 & 17864 & \pm 14005 \\
1984 & 23549 & 36265 & \pm 25589 \\
1993 & 33000 & 50820 & \pm 14841 \\
2001 & 52329 & 80533 & \pm 14559 \\
\hline
\end{tabular}


$\gamma_{i}$ is the growth probability (and is equivalent to the reciprocal of the stage duration), $m_{i}$ is the number of female births per female of stage $i$ per year, $P_{i}$ is the probability of surviving and remaining in the same stage, $G_{i}$ is the probability of growing and surviving to the next stage and $F_{i}$ is the reproductive output (births, $m_{i}$, multiplied by the probability of offspring survival). The term $F_{2}$ for reproductive output of subadults represents individuals that mature and reproduce during the projection interval. $\lambda$ (the finite rate of increase, i.e. $\lambda=e^{r}$ ) was calculated as the dominant eigenvalue of the projection matrix.

\section{Fertility control}

Fertility control was modelled as a reduction in mean offspring production $\left(m_{i}\right)$. The reduction was proportional to maximum offspring production and ranged from 90 to $10 \%$ of maximum offspring production in $20 \%$ decrements (Table 2). Fertility control only affected female camels and, for the purpose of this study, we did not include any compensatory increase in either offspring or sterile female survivorship, which has been observed in other vertebrates subjected to fertility control (Twigg et al. 2000; Saunders et al. 2002). Compensatory effects on ungulates following fertility control have previously been modelled as improvements in recruitment following reductions in population size (e.g. Hobbs et al. 2000), which is the expected density

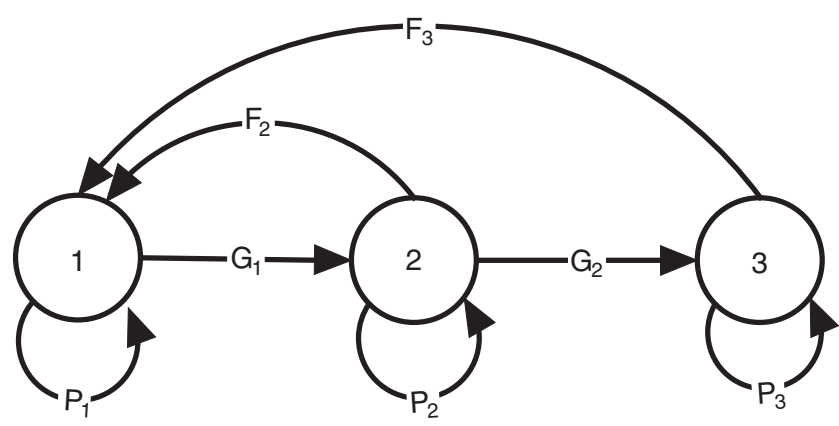

Fig. 3. Life-cycle corresponding to the projection matrix (Fig. 4). Stages are shown as circles. Stage 1 is yearlings, stage 2 is subadults (ages 1-5) and stage 3 is adults (ages 6-40).

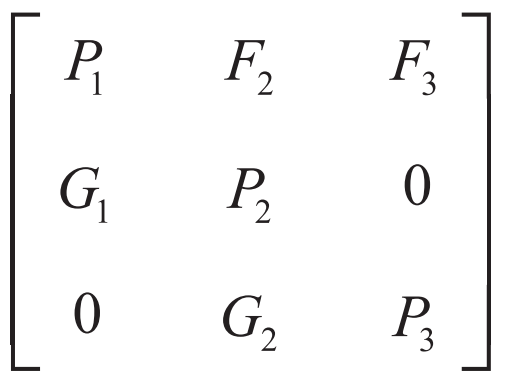

Fig. 4. Projection matrix for a stage-classified feral camel population. $G_{i}$ is the transition probability of moving from stage $i$ to stage $i+1, P_{i}$ is the transition probability of surviving and remaining in the same stage and $F_{i}$ is the stage-specific fertility. Because the duration of the yearling stage is the same as the projection interval, $P_{1}=0$. dependent response (Gaillard et al. 1998). The population growth that was modelled here was density independent.

\section{Results}

\section{Unstructured models}

The exponential growth model (Model 1) provided a good fit to the observed data (Fig. 5). The likelihood profiles for the two parameters of the model, initial population size $\left(N_{0}\right)$ and $r_{m}$, indicate that the parameters could be estimated with reasonable confidence (Fig. 6; Table 3). We note that the estimated rate of increase is more correctly termed the maximum observed rate rather than the maximum rate. It is only our interpretation that labels it the latter.

The logistic growth model (Model 2) also provided a good fit to the observed data. The likelihood profiles revealed that $N_{0}$ and $r_{m}$ could be estimated with confidence, but not carrying capacity $K$. The likelihood profile for $K$ was 'flat' and an upper $95 \%$ confidence interval could not be calculated (at least not a biologically meaningful estimate) (Table 3 ).

The theta-logistic growth model (Model 3) also provided a good fit to the observed data. Again, $N_{0}$ and $r_{m}$ could be estimated with reasonable precision, but not $K$ and theta (Table 3 ).

Models were compared using second order information criteria (Table 4). Although all models provided a reasonable fit to the observed data, the exponential growth model (Model 1) provided the best approximation for the observed data (Table 4). This result supports the view that the feral camel population in the Northern Territory has been growing exponentially (Edwards et al. 2004), at least until 2001 when the

Table 2. The calculated reduction in mean offspring production $\left(m_{i}\right)$ resulting from fertility control in stages $i=2$ and 3

\begin{tabular}{lcc}
\hline $\begin{array}{l}\text { Percent remaining } \\
\text { reproductive }\end{array}$ & $m_{2}$ & $m_{3}$ \\
\hline 100 & 0.202 & 0.236 \\
90 & 0.182 & 0.212 \\
70 & 0.141 & 0.165 \\
50 & 0.101 & 0.118 \\
30 & 0.061 & 0.071 \\
10 & 0.020 & 0.024 \\
\hline
\end{tabular}

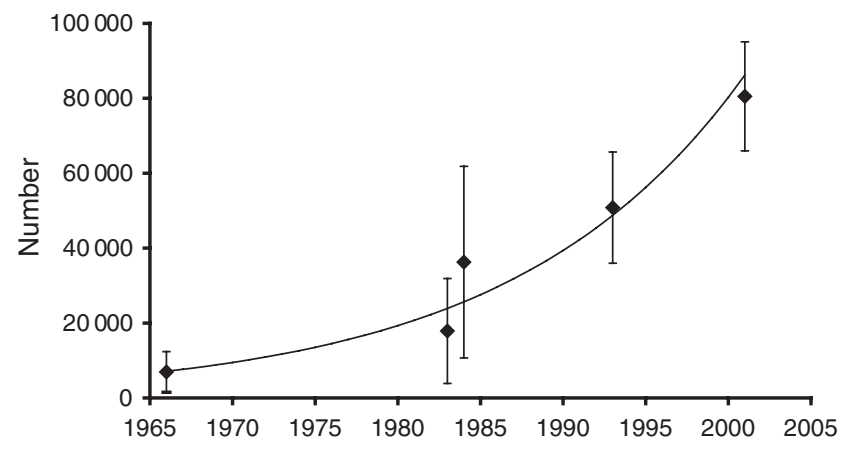

Fig. 5. Plot of camel abundance estimated from aerial surveys in Northern Territory (Short et al. 1988; Edwards et al. 2004), after correction for visibility bias. The fitted line is an exponential growth model (Model 1). Error bars represent $95 \%$ confidence intervals. 

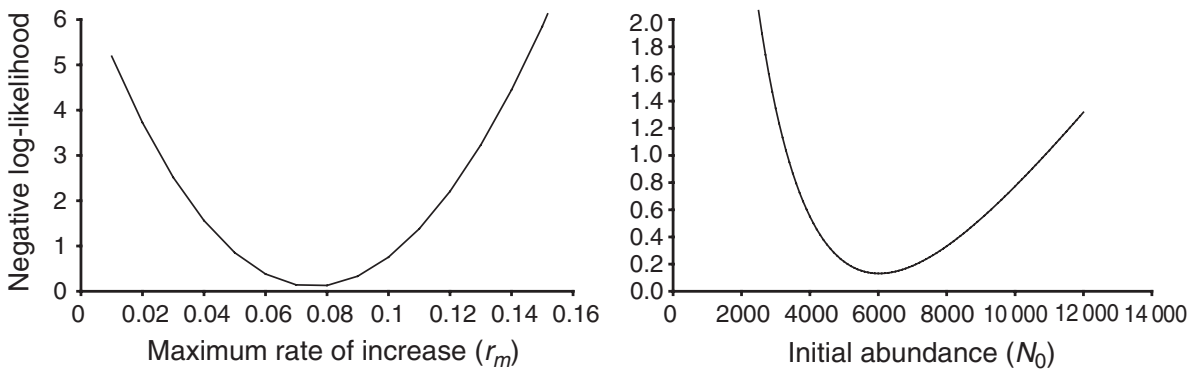

Fig. 6. Likelihood profiles for $r_{m}$ and $N_{0}$ (Model 1).

Table 3. Fitted parameter values and $95 \%$ confidence intervals for three models of potential population growth fitted to data in Table 1 $r_{m}$, Maximum exponential rate of increase; $N_{0}$, initial population size; $K$, carrying capacity; $\theta$, a parameter affecting the strength of density dependence relative to $K$

\begin{tabular}{lcrcc}
\hline Model no. & Parameter & Value & Lower 95\% CI & Upper 95\% CI \\
\hline 1 & $r_{m}$ & 0.074 & 0.04 & 0.12 \\
& $N_{0}$ & 7122 & 2700 & 14700 \\
& $r_{m}$ & 0.076 & 0.04 & 0.15 \\
& $N_{0}$ & 7060 & 2800 & 19400 \\
& $K$ & 262000 & 22000 & (undefined) \\
& $r_{m}$ & 0.079 & 0.035 & 0.15 \\
& $N_{0}$ & 7060 & 2600 & 18000 \\
& $K$ & 266700 & 22000 & (undefined) \\
& $\theta$ & 0.79 & 0.17 & (undefined) \\
\hline
\end{tabular}

Table 4. Negative log-likelihoods and AICc for the 3 models Most support is for the exponential growth model (Model 1). J is the number of parameters in the model, $L_{t}$ is the minimised negative log-likelihood and AICc is the second order information criterion (Burnham and Anderson 1998)

\begin{tabular}{lccc}
\hline Model no. & $\mathrm{J}$ & $\mathrm{L}_{\mathrm{t}}$ & $\mathrm{AICc}$ \\
\hline 1 & 2 & 0.106 & 9.79 \\
2 & 3 & 0.101 & 29.8 \\
3 & 4 & 0.101 & $-{ }_{\mathrm{A}}$ \\
\hline
\end{tabular}

${ }^{\mathrm{A}} \mathrm{AICc}$ could not be calculated for Model 3 because of the large number of parameters $(\mathrm{J}=4)$ relative to the number of data points $(n=5)$.

last survey data were collected. Assuming that exponential growth has continued, the 2008 population size would be $\sim 142000$ animals. Furthermore, there is currently no evidence from the aerial survey data that the feral camel population is approaching carrying capacity, nor can carrying capacity be estimated from the available data. A caveat to these results is that there are only five data points, so it is logical that the simplest model has been selected.

The estimate of $r_{m}$ is almost identical to that estimated by Edwards et al. (2004) who also used a regression model, but fitted it using least-squares. A simple linear regression model of these data identifies $N$ for 2001 and particularly $N_{0}$ as influential points as they are at the ends of the time series. Edwards et al. (2004) used a value of 5200 for $N_{0}$ based on McKnight's (1969) interviewbased survey, but this value results in a poorer fit than the value estimated here. We included $N_{0}$ as a variable that needed to be estimated, since the starting value of the population was highly uncertain. If population growth has been constant since 1966, then $N_{0}$ is likely to have been much higher than McKnight's (1969) estimate.

\section{Stage-structured model}

The initial transition probabilities derived from Dörges and Heucke (1995) produced the initial projection matrix A.

$$
\mathbf{A}=\left[\begin{array}{ccc}
0 & 0.00974 & 0.245 \\
0.843 & 0.768 & 0 \\
0 & 0.192 & 0.933
\end{array}\right]
$$

Optimal parameter values for the projection matrix, derived by minimising the sum-of-squared differences between the population projection and the best unstructured model, produced the projection matrix $\mathbf{A}^{\prime}$.

$$
\mathbf{A}^{\prime}=\left[\begin{array}{ccc}
0 & 0.0169 & 0.196 \\
0.848 & 0.791 & 0 \\
0 & 0.198 & 0.961
\end{array}\right]
$$

Optimisation of the stage-specific vital rates (survival $\sigma_{\mathrm{I}}$, growth $\gamma_{i}$, and births $m_{i}$ ) resulted in small changes in the transition probabilities, indicating that the original estimates $(\mathbf{A})$ were close to the optimum values (Table 5). There were only small changes in survival probability, and the growth probabilities were fixed. Mean offspring production showed the largest changes.

The elasticity of $\lambda$ to changes in $P_{i}, G_{i}$ and $F_{i}$ indicates that adult survival has the greatest influence on the rate of population change. The elasticity matrix (E) shows that subadult and adult growth and survival proportionally contribute 0.853 to $\lambda$, but juvenile growth and survival contributes only 0.0724 and fertility contributes a further 0.0704 .

$$
\mathbf{E}=\left[\begin{array}{ccc}
0 & 0.00341 & 0.0670 \\
0.0724 & 0.202 & 0 \\
0 & 0.0670 & 0.584
\end{array}\right]
$$

The stage-structured model indicates that $\lambda$ for the population is 1.074 (i.e. $r=0.071$ ), which is close to the value for $\lambda$ derived from the best unstructured model (1.077). To stop the population growth, $\lambda$ must be reduced below 1. Following Caswell (2001, eqn 9.110 , p. 242), this could be achieved by a proportional reduction in adult survival of $-0.074 / 0.853=-0.868$ (i.e. an $8.68 \%$ reduction), equivalent to a tripling of the natural mortality rate. 
Table 5. Initial and optimised values of stage-specific vital rates $\sigma_{\mathrm{I}}$ is survival probability, $\gamma_{\mathrm{I}}$ is growth probability and $m_{i}$ is the number of female births per female. Values for $\gamma_{1}, \gamma_{2}$ and $\gamma_{3}$ were fixed since they are age dependent

\begin{tabular}{lrc}
\hline Parameter & Initial value & Fitted (optimised) value \\
\hline$\sigma_{1}$ & 0.71 & 0.719 \\
$\sigma_{2}$ & 0.9605 & 0.989 \\
$\sigma_{3}$ & 0.9605 & 0.989 \\
$\gamma_{1}$ & 1 & 1 \\
$\gamma_{2}$ & 0.2 & 0.2 \\
$\gamma_{3}$ & 0.0286 & 0.0286 \\
$m_{1}$ & 0 & 0 \\
$m_{2}$ & 0.0602 & 0.202 \\
$m_{3}$ & 0.301 & 0.236 \\
\hline
\end{tabular}

\section{Fertility control}

Fertility control will reduce the rate of population growth but, to prevent population increase, the proportion of reproductive females that must be sterilised needs to be at least 70\% (Fig. 7). As quantified above, reducing the already low reproductive output of camels will only produce a modest reduction in rate of increase, certainly relative to a reduction in adult survival.

\section{Discussion}

\section{Population dynamics}

As expected from their large body size and compared with other mammals, camels have a particularly slow maximum population rate of increase of $7-8 \%$ per year, as determined by their vital rates. The actual rate is highly sensitive to the estimate of adult survival (e.g. $93 \%$ survival $=4 \%$ growth; $96 \%$ survival $=8 \%$ growth), highlighting the value of control methods targeting adult survival.

Historical survey data support a population trajectory for camels in the Northern Territory at close to this maximum rate, although the actual rate is sensitive to the initial, rough estimate in the 1960s. Despite the fact camels have occupied many areas of the southern Northern Territory for over 50 years, they do not appear to have reached carrying capacity where rate of increase would average zero over a large number of years. Edwards et al. (2004) estimated an annual exponential rate of increase of 0.093 $(\sim 10 \%)$ for the camel population between the two survey estimates of 1993 and 2001. Given the uncertainty in each of the density estimates, this rate of increase would have had a broad confidence interval and should not be extrapolated too far in time when more conservative estimates are available from a longer time series and from maximum rates based on camel demography.

The pattern of relatively slow population growth displayed by camels is an obvious advantage for control, with relatively few animals needing to be removed to keep $r \leq 0$. However, as can be seen from the yield curve (Fig. 2), an ever increasing number of animals are required to be removed to hold the population steady as density climbs almost to carrying capacity. In other words, the restraint on growth through density dependence provides little assistance for control of camel populations. This is not because camels are in a phase of establishment in central Australia (although that exacerbates the problem), but is a characteristic of established large mammal populations.

\section{Impact of harvesting}

To reduce population size it must obviously be harvested at a rate higher than it increases. To maintain a zero growth rate for the minimum estimate of the size of the 2001 Northern Territory camel population ( 80533 , Edwards et al. 2004) would require an annual harvest of $\sim 6200$ animals, assuming that the exponential rate of increase remains 0.074 . To hold the projected 2008 population of 142000 camels at zero growth would require an annual harvest of $\sim 10900$ camels. However, this ignores spatial variation in both camel density and any potential harvest (see McLeod and Pople 2010 [this issue]), their unpredictable movement over large areas, and immigration from the broader national population (Saalfeld and Edwards 2008). The ability of harvesting to hold a population at a particular density will depend on the harvester's functional response, which describes how the consumption or offtake rate changes in response to changes in the density of prey (Holling 1959; McCallum 2000). In this case, the offtake from all harvesters is considered so it is more

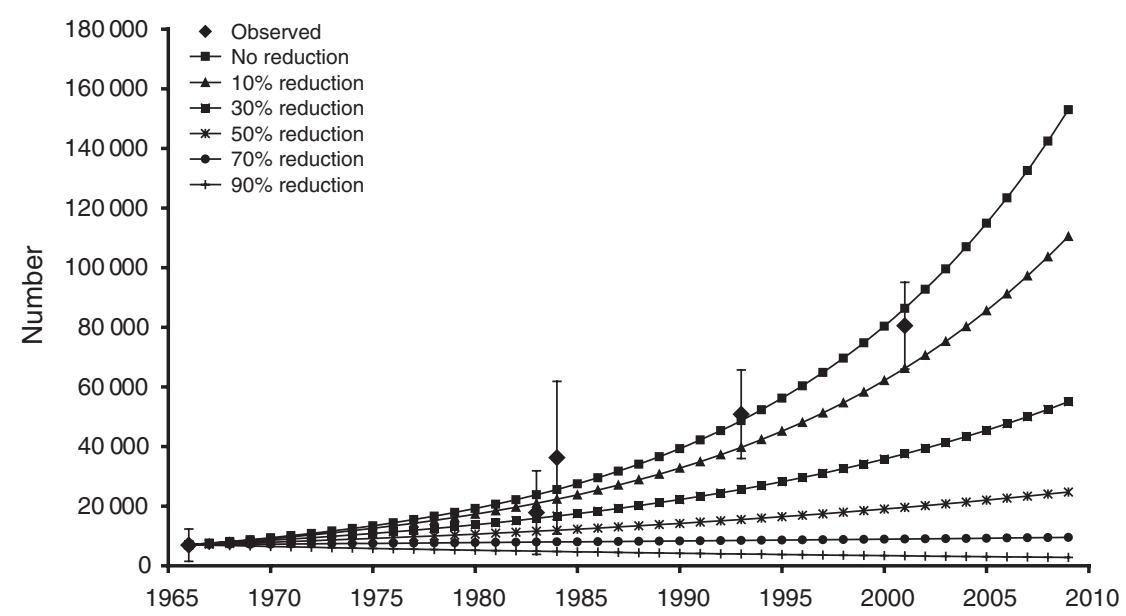

Fig. 7. Reduction in population size realised by a range of fertility control programs that sterilise up to $90 \%$ of reproductive females. 
appropriately termed the total response. Typically this function will reach an asymptote as there will be an upper limit to offtake dictated by factors such as numbers of harvesters, market availability and processing infrastructure. The latter two factors are equivalent to predator satiation. Conversely, at low densities, prey are difficult to find or it is simply not economically worth harvesting because of small returns.

Likely functional responses for camel harvesting are shown in Figs $8-10$. These are hypothetical, as is the height of the sustained yield curve (determined here by an unknown $K$ ) and its skewness (determined here by a suggested $\theta$ ). Currently, insufficient numbers of animals are being removed on a broad scale to stop the population from growing, and this is shown graphically in Fig. 8. Warfield and Tume (2000) reported a game meat harvest of 250-350 per year for the Northern Territory in the late 1990s, whereas Zeng and McGregor (2008) reported this live wild harvest across Australia to be 400-1000 per year for 2001-2008. Ramsay (1994) was unable to quantify the number field-shot for pet meat, but Zeng and McGregor (2008) reported a growing industry that in 2007 harvested 2700-3200 camels in Western Australia and 900-1400 animals in South Australia and the Northern Territory. In addition, an average of 250 camels were exported live from Australia over 1988-2007 (Zeng and McGregor 2008). This Australia-wide harvest of 5000-6000 per year represents less than $0.1 \%$ of the estimated population in 2007 of possibly one million camels (Saalfeld and Edwards 2008). Nevertheless, local reductions would be possible from these harvests.

Looking to the future, if the value of camels is increased, then offtake should also increase, all else being equal. There would then be the potential to suppress camel numbers to a low density. However, as shown in Fig. 9, above some moderate density, the population could still escape this 'predator pit' (Pech et al. 1995) and continue to grow to an equilibrium just short of carrying capacity. A further possible scenario is shown in Fig. 10. Here, it is economic to harvest camels at low density because harvesters have good access to them and the harvesters continue to operate because they have alternative and more abundant species (e.g. feral horses, donkeys and domestic cattle) to harvest. Nevertheless, commercial harvesting of feral goats has not lead

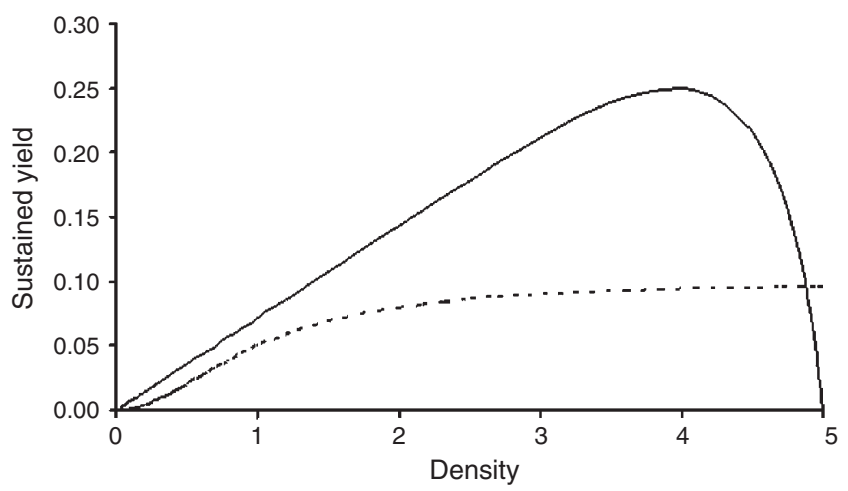

Fig. 8. Sustained yield curve (solid line) for a camel population (see Fig. 2) and a sigmoidal Type III functional response (dashed line) (Holling 1959) for their harvest. The population continues to grow to an equilibrium at relatively high density just short of carrying capacity. to suppression of populations to low numbers, despite their occurrence in less remote areas than camels and a substantial rise in their value in the mid-1990s (Parkes et al. 1996; Pople et al. 1996; A. R. Pople et al., unpubl. data). In contrast, camels have a much lower rate of increase increasing the chances of successful control.

\section{Fertility control}

Reducing the fertility of camels is likely to be a highly inefficient form of population control. Camels are widely dispersed in the Northern Territory and potential methods of contraceptive delivery, such as darting or food baiting, would be very expensive and logistically difficult to achieve on a broad scale. The elasticity analysis and age-structured modelling indicated that reducing fertility of females will result in only modest reductions in the rate

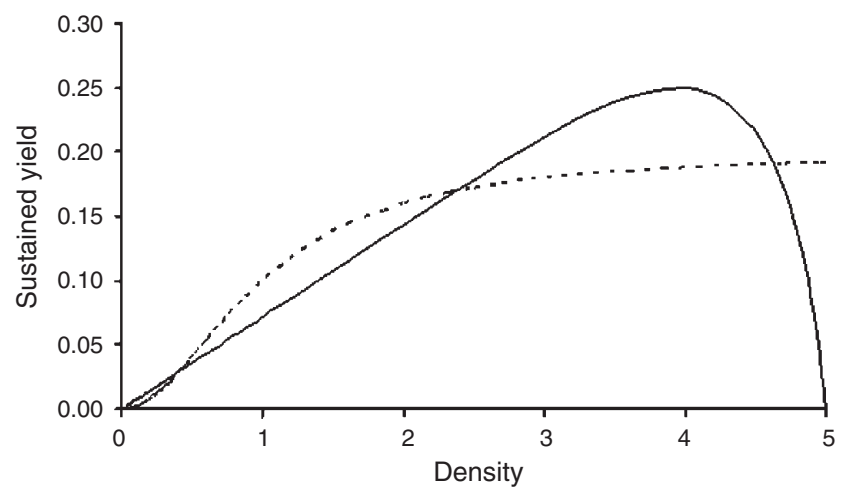

Fig. 9. Sustained yield curve (solid line) for a camel population (see Fig. 2) and a Type III functional response (dashed line) (Holling 1959) for their harvest. In contrast to the functional response shown in Fig. 8, the value of camel products has been increased allowing a higher harvest at low densities. Below $\sim 2$ camels $/ \mathrm{km}^{2}$, population growth is suppressed by harvesting to a density below $1 \mathrm{camel} / \mathrm{km}^{2}$. If the population is above $\sim 2.5$ camels $/ \mathrm{km}^{2}$, the population continues to grow to an equilibrium at relatively high density just short of carrying capacity.

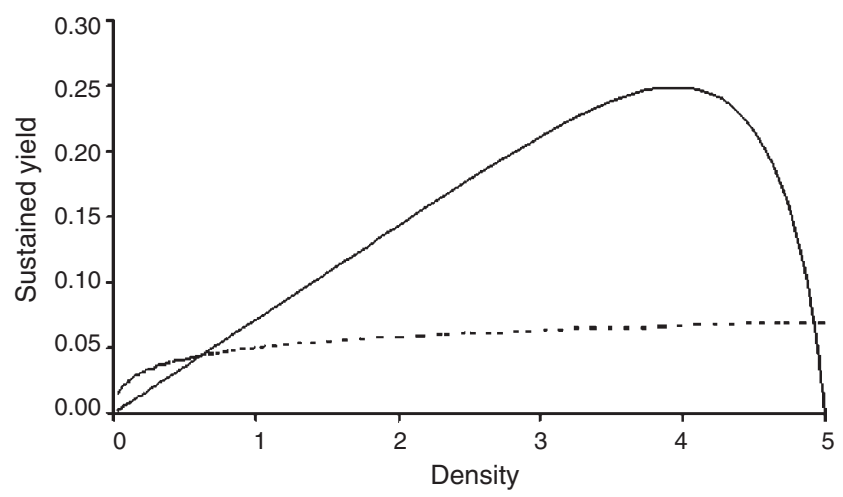

Fig. 10. Sustained yield curve (solid line) for a camel population (see Fig. 2) and a Type II functional response (dashed line) (Holling 1959) for their harvest. In contrast to the functional response shown in Fig. 8, alternative species are available for harvest allowing the camel harvest to continue at low camel densities. In contrast to Figs 8, 9, the population can be harvested to very low density or even to local extinction, as there is no low density refuge and so the response is convex (cf. sigmoidal) throughout. 
of population increase unless high rates of infertility can be achieved. The required high $(>50 \%)$ proportion of females sterilised to stem population growth is consistent with results for other modelled ungulate populations (see Hobbs et al. 2000).

Fertility control of wild camels in the Northern Territory is currently not a viable option for management on a broad scale and it is unlikely that the substantial technological hurdles will be overcome in the near future. The most effective method of longterm population reduction will rely on increasing mortality of adults.

\section{Acknowledgements}

We would like to thank Peter Whitehead for providing comments on a draft. Comments by Mark Lethbridge and an anonymous reviewer also improved a previous version of the manuscript. The work reported in this publication is supported by funding from the Australian Government Natural Heritage Trust through the Desert Knowledge CRC; the views expressed herein do not necessarily represent the views of the Australian Government or the Desert Knowledge CRC or its participants.

\section{References}

Burnham, K. P., and Anderson, D. A. (1998). 'Model Selection and Inference: a Practical Information-theoretic Approach.' (Springer-Verlag: Berlin.)

Carey, J. R., and Judge, D. S. (2001). Life span extension in humans is selfreinforcing: a general theory of longevity. Population and Development Review 27, 411-436. doi:10.1111/j.1728-4457.2001.00411.x

Caswell, H. (2001). 'Matrix Population Models.' (Sinauer Associates: Sunderland, MA.)

Dörges, B., and Heucke, J. (1995). Ecology, social organisation and behaviour of the feral dromedary Camelus dromedarius (L 1758) in central Australia. Unpublished translation of two Dissertations, University of Braunschweig, Braunschweig, Germany.

Eberhardt, L. L. (1987). Population projections from simple models. Journal of Applied Ecology 24, 103-118. doi:10.2307/2403790

Edwards, G. P., Eldridge, S. R., Wurst, D., Berman, D. M., and Garbin, V. (2001). Movement patterns of female feral camels in central and northern Australia. Wildlife Research 28, 283-289. doi:10.1071/WR00053

Edwards, G. P., McGregor, M., Zeng, B., Saalfeld, W. K., Vaarzon-Morel, P., and Duffy, M. (2008b). Synthesis and key recommendations. In: 'Managing the Impacts of Feral Camels in Australia: a New Way of Doing Business'. DKCRC Report 47. (Eds G. P. Edwards, B. Zeng, W. K. Saalfeld, P. Vaarzon-Morel and M. McGregor.) (Desert Knowledge Cooperative Research Centre: Alice Springs.)

Edwards, G. P., Saalfeld, K., and Clifford, B. (2004). Population trend of feral camels in the Northern Territory. Australian Wildlife Research 31 509-517. doi:10.1071/WR03073

Edwards, G. P., Zeng, B., and Saalfeld, W. K. (2008a). Evaluation of the impacts of feral camels. In: 'Managing the Impacts of Feral Camels in Australia: a New Way of Doing Business'. DKCRC Report 47. (Eds G. P. Edwards, B. Zeng, W. K. Saalfeld, P. Vaarzon-Morel and M. McGregor.) (Desert Knowledge Cooperative Research Centre: Alice Springs.)

Fowler, C. W. (1981). Comparative population dynamics in large mammals. In: 'Dynamics of Large Mammal Populations'. (Eds C. W. Fowler and T. D. Smith.) pp. 437-455. (John Wiley \& Sons: New York.)

Fowler, C. W. (1987). A review of density dependence in populations of large mammals. In: 'Current Mammalogy'. (Ed. H. H. Genoways.) pp. 401-441. (Plenum Press: New York.)

Gaillard, J., Festa-Bianchet, M., and Yoccoz, N. G. (1998). Population dynamics of large herbivores: variable recruitment with constant adult survival. Trends in Ecology \& Evolution 13, 58-63. doi:10.1016/S01695347(97)01237-8
Graham, A., Johnson, K., and Graham, P. (1986). An aerial survey of horses and other large animals in the Alice Springs and Gulf regions. Technical Report No. 28, Conservation Commission of the Northern Territory, Alice Springs.

Grigg, G. C., Pople, A. R., and Beard, L. A. (1995). Movements of feral camels in central Australia determined by satellite telemetry. Journal of Arid Environments 31, 459-469. doi:10.1016/S0140-1963(05)80129-6

Hilborn, R., and Mangel, M. (1997). 'The Ecological Detective.' (Princeton University Press: Princeton, NJ.)

Hobbs, N. T., Bowden, D. C., and Baker, D. L. (2000). Effects of fertility control on populations of ungulates: general, stage-structured models. Journal of Wildlife Management 64, 473-491. doi:10.2307/3803245

Holling, C. S. (1959). The components of predation as revealed by a study of small-mammal predation of the European pine sawfly. Canadian Entomologist 91, 293-320. doi:10.4039/Ent91293-5

Hone, J. (1992). Rate of increase and fertility control. Journal of Applied Ecology 29, 695-698. doi: 10.2307/2404478

Lapidge, S. J., Eason, C. T., and Humphrys, S. T. (2008). 'A Review of Chemical, Biological and Fertility Control Options for the Camel in Australia.' DKCRC Research Report 51. (Desert Knowledge Cooperative Research Centre: Alice Springs.)

McCallum, H. (2000). 'Population Parameters.' (Blackwell Science: London.)

McKnight, T. L. (1969). 'The Camel in Australia.' (Melbourne University Press: Melbourne.)

McLeod, S. M., and Pople, A. R. (2010). Modelling the distribution and relative abundance of feral camels in the Northern Territory using count data. The Rangeland Journal 31, 21-32.

Parkes, J. P., Henzell, R. P., and Pickles, G. S. (1996). 'Managing Vertebrate Pests: Feral Goats.' (Australian Government Publishing Service: Canberra.)

Pech, R. P., Sinclair, A. R. E., and Newsome, A. E. (1995). Predation models for primary and secondary prey species. Wildlife Research 22, 55-64. doi:10.1071/WR9950055

Pople, A. R., Grigg, G. C., Cairns, S. C., Alexander, P., Beard, L. A., and Henzell, R. P. (1996). Trends in the numbers and changes in the distribution of feral goats (Capra hircus) in the South Australian pastoral zone. Wildlife Research 23, 687-696. doi:10.1071/WR9960687

Ramsay, B. J. (1994). 'Commercial Use of Wild Animals in Australia.' (Australian Government Publishing Service: Canberra.)

Rockwood, L. L. (2006). 'Introduction to Population Ecology.' (Blackwell Publishing: London.)

Saalfeld, W. K., and Edwards, G. P. (2008). Ecology of feral camels in Australia. In: 'Managing the Impacts of Feral Camels in Australia: a New Way of Doing Business'. DKCRC Report 47. (Eds G. P. Edwards, B. Zeng, W. K. Saalfeld, P. Vaarzon-Morel and M. McGregor.) pp. 9-34. (Desert Knowledge Cooperative Research Centre: Alice Springs.)

Saalfeld, W. K., and Zeng, B. (2008). Review of non-commercial control methods for feral camels in Australia. In: 'Managing the Impacts of Feral Camels in Australia: a New Way of Doing Business'. DKCRC Report 47. (Eds G. P. Edwards, B. Zeng, W. K. Saalfeld, P. Vaarzon-Morel and M. McGregor.) (Desert Knowledge Cooperative Research Centre: Alice Springs.)

Saunders, G., McIlroy, J., Berghout, M., Kay, B., Gifford, E., Perry, R., and Van De Ven, R. (2002). The effects of induced sterility on the territorial behaviour and survival of foxes. Journal of Applied Ecology 39, 56-66. doi:10.1046/j.1365-2664.2002.00696.x

Short, J., Caughley, G., Grice, D., and Brown, B. (1988). The distribution and relative abundance of camels in Australia. Journal of Arid Environments 15, 91-97.

Twigg, L. E., Lowe, T. J., Martin, G. R., Wheeler, A. G., Gray, G. S., Griffin, S. L., O'Reilly, C. M., Robinson, D. J., and Hubach, P. H. (2000). Effects of surgically imposed sterility on free-ranging rabbit populations. Journal of Applied Ecology 37, 16-39. doi:10.1046/j.1365-2664.2000.00471.x 
Warfield, B., and Tume, L. (2000). 'Marketing Analysis and Plan for the Camel Industry.' (Rural Industries Research and Development Corporation: Canberra.)

Wurst, D., and Saalfeld, W. K. (1994). Aerial survey of feral camels and other large vertebrate species in the Alice Springs region of the Northern Territory. Parks and Wildlife Commission of the Northern Territory Final Report to the Australian Nature Conservation Agency, Canberra.
Zeng, B., and McGregor, M. (2008). Review of commercial options for management of feral camels. In: 'Managing the Impacts of Feral Camels in Australia: a New Way of Doing Business'. DKCRC Report 47. (Eds G. P. Edwards, B. Zeng, W. K. Saalfeld, P. Vaarzon-Morel and M. McGregor.) pp. 221-282. (Desert Knowledge Cooperative Research Centre: Alice Springs.)

Manuscript received 31 July 2009; accepted 3 December 2009 